\title{
Good for Samsung is Good for Korea: Image Restoration Strategies Used by Samsung After a Whistle-Blowing Corruption Scandal
}

\author{
Taejin Jung*,1, Ron Graeff ${ }^{1}$ and Woomi Shim ${ }^{2}$ \\ ${ }^{I}$ Communication Studies Department, State University of New York at Oswego, USA; ${ }^{2}$ Department of Communication, \\ Florida State University, USA
}

\begin{abstract}
This study sought to examine the image restoration and renewal strategies a prestigious South Korean company (Samsung) employed in responding to the allegations of wrongdoing made by a whistler-blower. Review of official comments and documents found that the organization used defensive strategies (e.g., transcendence, denial, attack the accuser, bolstering) in order to protect its image. Among defensive strategies, the "transcendence" image restoration strategy was the most effective one and successfully made the South Korean public to believe that a few misconducts done by Samsung should be justified to protect the national economy from fierce global economic competitions. Even though crises can be used as a chance for image restoration and organization renewal, Samsung did not carry meaningful and observable actions that essentially renew or correct the problems.
\end{abstract}

Keywords: Samsung, Image restoration strategies, whistle-blowing, crises.

\section{INTRODUCTION}

Crisis communication is a growing field of study due in part to the probability and high impact of recent crises such as Hurricane Katrina, BP oil spill and the financial crisis caused by the mortgage meltdown. On the stage of crisis, strategic communication is particularly critical and challenging to the crisis management team, because it must immediately build the crisis management rhetoric that is favorable to the organization and explains how and why the misdeeds or catastrophe occurred (Ulmer, Seeger, \& Sellnow, 2007). Credible rhetoric is the core component of crisis communication to restore and renew the organization's image (Elwood, 1995).

Among wide range of crises, allegations of organizational wrongdoings continue to surface in the media, along with natural disaster, workplace violence, rumors, malevolence etc. (Coombs, 2007; King, 2006). When an accusation is made by a disgruntled insider (e.g., whistleblower) against a company, a crisis management team finds itself in an awkward position, especially when the crisis management team did not prepare for the whistle-blowing allegations of misconducts against top management. When whistle blowing allegations appeared in the media, Samsung (a leading South Korean conglomerate)'s crisis management team tried to structure the information environment on its behalf, thus portraying Samsung favorably in the perceptions of key stakeholders. This study has examined various image restoration and renewal strategies a prestigious South Korean company employed after having a whistle-blowing attack by a disgruntled insider.

*Address correspondence to this author at the School of Communication, Media \& the Arts, 7 Lanigan Hall, SUNY Oswego, Oswego, NY 13126, USA; Tel: 315.312.3527; Fax: 315.312.5658; E-mail: jung@oswego.edu
Samsung is the biggest Chaebol (family-controlled conglomerate) in South Korea with 59 affiliates and 250,000 employees globally. Samsung is referred to the backbone of the South Korean economy, which accounts for nearly twenty percent of South Korea's total exports and fifteen percent of GDP. In 2006, Samsung was recognized as the $13^{\text {th }}$ largest company in the world economy by the World Bank (Choe, 2007a). The significant position of Samsung in domestic as well as international economy places Samsung in the category of "too big to fail."

On October 29 of 2007, a whistle-blower, Kim Yongchul, a former director of Samsung's legal department (1997 2004), urged an investigation into Samsung's suspected bribery activities, including charges of bribery lodged by the prestigious Korean Catholic Priests' Association for Justice, an organization that stands for moral justice in Korean society. Kim and the Catholic Priests' Association claimed that "Samsung had stashed away a massive slush fund over 1,000 bank accounts that were created under the names of the company's executives. The association said "part of the money was spent on bribing prosecutors, politicians, government officials, media and civil activists" (Song, 2007a). Immediately after Kim's allegations, public prosecutors were set to begin an independent investigation. The three main accusations against Samsung were: (1) the creation of Samsung's alleged slush fund, (2) the bribery of prosecutors and other government officials, and (3) the illicit transfer of managerial rights to Lee Jae-yong, son of the current Samsung chairman Lee Kun-hee (Kim, 2007b). As has been widely reported, many problems with Samsung stem from the Lee family's desire to continue maintenance of corporate control through illicit and covert financial practices (Song, 2008b). Financial analysts and civil activists in Korea have long speculated that all the corrupt financial practices of 
Samsung have been orchestrated by the Samsung family to facilitate the father-to-son succession of wealth.

From the day after the press conference was conducted by Mr. Kim and the Catholic Priests' Association, Samsung flatly rejected all the allegations as "groundless" and attributed the whistle-blowing to Mr. Kim's personal grudges against Samsung. After initially denying most allegations, two executives of Samsung who were accused of managing a slush fund filed a libel lawsuit against the whistle-blower Kim Yong-chul for defaming them with groundless allegations. In addition to those denials, three prosecutors who were suspected of taking bribes from Samsung, according to the Kim's allegations, also flatly denied their alleged corrupt ties with Samsung (Song, 2007b). A week after the allegations, Samsung issued a 25page news releases that denied, one by one, all major charges by the former Samsung attorney, discrediting them as not having solid evidences (Choe, 2007a).

Like the brief summary described above, Samsung's crisis management team responded to Kim's allegations in various forums. It is these response strategies that this study will explore through examining the contents in the reports of mainstream media outlets. By examining the image restoration strategies of Samsung's crisis management team, we can gain a better understanding of why a certain strategy was chosen to deal with specific allegations of wrongdoing and whether the strategy was effective in a unique Korean business culture in the short and long term basis.

\section{LITERATURE REVIEW}

\subsection{Image Restoration Theory}

Whistle-blowing has been defined by Near \& Miceli $(1985$, p. 4$)$ as the "disclosure by organizational members (former or current) of illegal, immoral, or illegitimate practices under the control of their employers, to persons or organizations that may be able to effect action." In a broader context, Coombs \& Holladay (2002) defined the crisis type of "challenge" as "confrontation by disgruntled stakeholders claiming an organization is operating in an inappropriate manner" (p. 170). In the event a whistle-blower goes to the public with allegations of organizational wrongdoing, the crisis management team should immediately adopt appropriate response strategies. One widely used response tool is the image restoration strategies developed by Benoit (1995).

Benoit's (1995) image restoration theory is considered a valuable tool to examine efforts for rebuilding a tarnished reputation. There are many cases that illustrate Benoit's image restoration theory (Benoit, 2006; Benoit \& Brinson, 1999; Benoit \& Czerwinski, 1997; Brinson \& Benoit, 1999; Coombs \& Schmidt, 2000; Len-Rios \& Benoit, 2004; Zhang $\&$ Benoit, 2004). Extensive applications and articulations of image restoration theory have happened through many case studies that are heavily descriptive and retrospective. Even though the theory has limitations as to its predictive power and causal inference, it provides valuable insights and practical guidelines for the crisis management practitioners (Coombs \& Schmidt, 2000). The core of image restoration theory is a set of image restoration strategies. The theory argues that there are five general options available for image defenses: denial, evasion of responsibilities, reducing offensiveness of the event, corrective action, and mortification (see Table 1).

A denial strategy argues that the organization did not do anything wrong or was not involved in any wrongdoing. Evasion of responsibility means that the organization has only limited responsibility or the crisis happened by accident. Reducing the offensiveness of the act tries to convince stakeholders that the damage is minimal and the crisis is therefore less threatening. Corrective action is a determination to recover from the current damage and to prevent a repetition of crisis. Mortification is an acceptance of responsibility and requires the company or CEO to issue an apology.

\subsection{Developmental Stages of the Scandal}

Samsung's slush fund scandal has followed stages of development after the whistle-blower first lashed out at Samsung, and different response strategies emerged from the Samsung's official news releases and comments by Samsung officials. In order to provide a process of the scandal development as well as a clear assessment of response strategies, the period of October 2007 and through April 2008 was divided into three categories, namely (1) the whistle-blowing, (2) investigation by public prosecutors, (3) investigation by special council. Within each category, image restoration strategies used by Samsung are illustrated while considering the social and political context over the period of investigation. The following are two main research questions applied to the analyses of each crisis stage.

RQ1: What were the predominant image restoration strategies used by Samsung to counteract allegations of wrongdoing made by a whistle-blower?

RQ2: How effective were Samsung's response strategies in restoring its reputation?

\section{METHODS}

In order to examine crisis response strategies employed by Samsung, an official 25-page news released by Samsung and news reports on Samsung's responses to the allegations were collected. News reports were collected through the LexisNexis Academic by using the key words of the allegations (e.g., Samsung, whistle-blower, slush fund, and bribery). 23 different articles were collected from the two South Korean major English newspapers (The Korea Herald and Korea Times), prestigious foreign newspapers (The New York Times (The International Herald Tribune) and LA Times), one foreign broadcasting company (BBC), and one foreign magazine (Newsweek). News reports covering the Samsung slush fund crisis were examined from the date of the charges made by the whistle-blower (October 29, 2007) through the period of April 23, 2008, ending when the inquiry of special counsel expired. Articles were read, focusing only on the "direct quotes" from Samsung internal sources (e.g., CEOs, spokespersons etc.) who were responding to the allegations made by Kim Yong-chul. The official 23-page news release issued by Samsung was also considered for the analyses of rhetorical image restoration strategies. Over the analyses, five general categories of image repair strategies are identified: denial, attack the accuser, bolstering, transcendence, and mortification. 


\section{RESULTS}

Over the course of the whistle-blowing crisis, Samsung used image restoration strategies that fell toward advocacy to protect itself at the early and middle stages and began to accept the accommodative ones on behalf of stakeholder publics after the special council's final report. Simple denial and attacking the accuser are the two main advocate strategies and are mainly employed at the early stage of crisis and continue until the end phase of the investigation. Bolstering and transcendence have been overarching image repair strategies during the crisis. The most appealing strategy of transcendence in this case can be a mixture of justification and ingratiation. Samsung implied its alleged wrongdoing didn't happen, downplayed its severity (e.g., justification) and kept emphasizing its economic contributions on the local and national economy (e.g., ingratiation). Mortification used at the final stage of crisis is the most accommodative strategy.

\subsection{Simple Denial}

Denial is an assertion that the allegations did not occur, or the accused did not commit the wrongdoing (Coombs \& Holladay, 2002; Cooms \& Holladay, 2002; Len-Rios \& Benoit, 2004). Crisis managers use simple denial strategy to separate their company from the offenses. Facing a potent insider whistle-blower, a Samsung spokesman flatly denied all of Mr. Kim's allegations from the outbreak of the whistling-blowing, saying that "the accusations were groundless" (Choe, 2007a). Samsung chairman Lee Kun-hee even denied the corruptive wrongdoings in the statement to the special counsel, and said that "Whether the allegations are true or not, I believe that this should not happen again.... I do not believe Samsung is a criminal group" (Song, 2008a). In conjunction with the publicized denials against the Mr. Kim's allegations, Samsung issued a 25 page rebuttal news release denying all major charges made by Mr. Kim. The document tried to explain the background of the incidents and how Mr. Kim's personal antipathy against Samsung led to the false allegations.

Against Mr. Kim's more specific allegation that a prosecutor-general nominee Lim, C.J. was bribed by Samsung, the Samsung spokesman said, "this is groundless and malicious slander to damage us." Mr. Lim also told reporters, "I have never received any bribe from Samsung. I am even not acquainted with Kim Yong-chul." (Jin, 2007). In response to the allegation by the Priests' Association for Justice about the illegal purchases of bonds and shares of Samsung's affiliates by Lee Jay-yong (son of Samsung chairman Lee Kun-hee), Samsung repudiated the allegation again, saying that "Samsung compiled the documented in 2003 and submitted it to prosecutors to rebut the claims of certain civic groups regarding illegal wealth transfers from the chairman to his son." (Jin, 2007). About Mr. Kim's allegations that chairman Lee Kun-hee's wife used the slush fund to buy expensive artworks including the $\$ 8$ million worth "Bethlehem's Hospital" by Frank Stella, Samsung again denied the allegations, saying that "the Samsung family never bought the paintings." (Kim, 2007c).

\subsection{Attack the Accuser}

A strategy of attacking the accuser is commonly used by the crisis manager to confront the group or person that claims a crisis exists(Coombs \& Holladay, 2002; Cooms \& Holladay, 2002). It is also a strategy to shift blame to the true culprit (Benoit, 2006). Samsung frequently used the response strategy of attacking the accuser at the early stage of whistleblowing. After a couple of weeks following Mr. Kim's allegations, two executives of Samsung, who have been claimed to handle illegal lobbying with top officials, filed a libel lawsuit against Mr. Kim. A South Korean business group also announced on behalf of the two Samsung executives that "Kim defamed us with groundless allegations" (Song, 2007a). In response to Kim's allegations of the Samsung chairman's wife and her in-laws' involvement of using slush funds to buy expensive artworks, the Joongang Daily (a prestigious South Korean newspaper owned by Samsung chairman's brother-in-law) flatly refuted Mr. Kim's claims, saying that "we consider Kim's fictitious allegations as libel and will thus take legal action" (Kim, 2007c).

Samsung chairman Lee Kun-hee even blamed the media at the appearance to the special counsel, saying that "I do not believe Samsung is a criminal group. I think the problem is with the media spreading such allegations to the public" (Song, 2008a). Through a 25 page rebuttal news release against Mr. Kim's allegations, Samsung consistently tried to lower Mr. Kim's credibility arguing that his allegations were out of his fragile moral standard and personal grudge on being demoted in the organization.

\subsection{Bolstering}

Bolstering emphasizes the dependant's positive qualities to counterbalance the accusations (Len-Rios \& Benoit, 2004). Benoit (2006, p. 138) refers to bolstering as "attempts to improve the audience's positive affect for the rhetoric to outweigh the offensiveness of the wrong action." Like other cases of image restoration after incessant scandals rocking South Korean conglomerates, Samsung has made most of the bolstering strategy by boosting its contribution to the national economy. With 59 affiliates and 250,000 employees globally, Samsung generated more than a fifth of the South Korean gross domestic product (e.g., $\$ 160$ billion worth in 2006). When Samsung issued formal statements including the 25 page rebuttal news release, it boasted its company tradition of transparent management and providing social benefits. Under the circumstances of widely corruptive business practices in South Korea, a column of in-depth analysis of the problem quoted an opinion of a head of an electronic parts maker, saying that "no matter what problems it might have, Samsung is still the cleanest and most competitive company we can depend on in this time of economic uncertainty" (Choe, 2007b).

\subsection{Transcendence}

When Samsung was hammered by many allegations, including illegal creation of a slush fund, the bribery of prosecutors and government officials, and illegal help for chairman Lee's son to take over control of Samsung, one of the most effective crisis response strategies appealing to the general public must be a "transcendence." The strategy of transcendence pertains to placing the misdeed in a broader context, namely comparing it to more important values (e.g., national economic well-being), so that the misdeeds become dwarfed when seen alongside the higher ends (Benoit, 2006; 
Table 1. Typology of Image Restoration Strategies

\begin{tabular}{|c|c|c|}
\hline Strategy & Key Characteristics & Example \\
\hline \multicolumn{3}{|l|}{ Denial } \\
\hline Simple denial & Did not perform act & Tylenol: did not poison capsules \\
\hline Shift the blame & Another performed act & Tylenol: a "madman" poisoned capsules \\
\hline \multicolumn{3}{|l|}{ Evasion of responsibility } \\
\hline Provocation & Responded to act of another & Firm moved because of new taxes \\
\hline Defeasibility & Lack of information/ability & Executive not told meeting was moved \\
\hline Accident & Mishap & Tree fell on tracks causing train wreck \\
\hline Good intentions & Meant well & Sears wants to provide good auto repair service \\
\hline \multicolumn{3}{|c|}{ Reducing offensiveness of event } \\
\hline Bolstering & Stress good traits & Exxon's "swift and competent" cleanup of oil spill \\
\hline Minimization & Act is not serious & Exxon: few animals killed in oil spill \\
\hline Differentiation & Act is less offensive & Sears: unneeded repairs were preventive maintenance, not fraud \\
\hline Transcendence & More important values & Helping humans justifies testing animals \\
\hline Attack accuser & Reduce accuser's credibility & Coke: Pepsi owns restaurants, competes directly with you \\
\hline Compensation & Reimburse victim & Disabled movie-goers given free passes after denied admission \\
\hline Corrective action & $\begin{array}{l}\text { Plan to solve/prevent } \\
\text { recurrent of problem }\end{array}$ & $\begin{array}{l}\text { AT\&T long-distance upgrade; promised to spend millions more to improve } \\
\text { service }\end{array}$ \\
\hline Mortification & Apology & AT\&T apologized for service interruption \\
\hline
\end{tabular}

Source: Zhang and Benoit (2004) \& Benoit (1997)

Len-Rios \& Benoit, 2004; Zhang \& Benoit, 2004). Through the rhetorical strategy of transcendence, Samsung crisis management team sought to motivate key stakeholders (e.g., shareholders, government, employees and cooperative companies) to stay with the organization and rebuild its image at least to a level of its pre-crisis status (Seeger \& Ulmer, 2002).

In a speech to the Samsung workers, vice chairman of Samsung Electronics, Yun Jong-yong, noted that "there was fear among shareholders and investors that this confusion may disrupt our management and national economy" (Choe, 2007b). At the press conference a week after the whistleblowing, Samsung said "with speculations and misunderstandings being disseminated, we have reached a situation where Samsung's corporate image and our global operations are put under a grave threat" (Song, 2007b). Taking stands against South Korea's opposition parties' request for the special investigation by an independent counsel into Samsung's alleged illegal lobbying, South Korea's five major business groups that are favorable to Samsung argued that "a special investigation into the company, which is the face of South Korea's business world, would inevitably damage the image of South Korean companies and the country as a whole globally" (Lee, 2007). The justice minister, Chung Soung-jin, also opposed the special investigation bill, saying that "this could have a negative impact on domestic businesses, as the probe would damage the credibility of Samsung and the government" (Kim, 2007a). Fearing that any prolonged probe might hurt the local economy, a head of pro-business group Sohn Kyung-shik said that "a possible prolonged probe could have a negative impact on the local economy as well as South Korea's credit ratings" (Song, 2007d). Samsung restated its unequivocal share of national economy and tried to connect local economic losses with the equivocal allegations against Samsung. In short, the costs of a few misconducts are justified by the need to protect national economy from the fierce global economic competitions.
The critical importance of Samsung on the South Korean economy was so ingrained in the mind of business leaders, the effect of image restoration strategy of transcendence is even more apparent to the South Korean opinion leaders. A statement made by the head of an electronic part maker association in South Korea elaborated on the importance of Samsung to the local economy: "Everyone is watching what's going to happen to Samsung. If Samsung takes a punch, we feel the shock, too. If Samsung shrinks because of the investigation and cuts its investment, smaller companies like us will shut down in droves" (Choe, 2007b). An economist at Hanyang University in South Korea added another instance of transcendence stating his equivocal sympathy about the accusations and Samsung: "Samsung is the spine of the economy. If it shakes, the economy shakes. If Samsung does something, it becomes the standard. But it never cast off the old vices of Chaebol. It's not free from corruption" (Choe, 2007b). Above all, the independent council prosecutors did not detain Samsung chairman Lee and nine other executives after indicting them on charges of breach of trust and tax evasion, saying that "we decided not to detain them in consideration of a negative impact on the economy" (Song, 2008a).

As a key image restoration strategy, Samsung consistently asserted that it has been performing a critical service for the national economy, justifying their misbehaviors. This is a clear instance of transcendence, an appeal to higher values: the costs of corruption are justified by the importance of supporting the economy for the benefit of the general public.

\subsection{Mortification}

Mortification is a strategy to admit committing the offensive act and beg forgiveness (Benoit, 1997; Benoit \& Brinson, 1999). The chairman of Samsung, after being interrogated by the independent council, told reporters that "it is all my fault. I will take all moral and legal 
responsibility" and added "I will seriously consider overhauling the group's management system and executives, including myself' (Song, 2008a). In line with chairman Lee's comments, president of Samsung's strategic planning announced its plan to revamp the conglomerate, saying that "we are sorry for causing concerns to the public. We will announce an overhaul plan after hearing opinions from all side of society" (Lee \& Jin, 2008).

\section{DISCUSSIONS}

This research applied Benoit's image restoration theory to analyze the message strategies of the Samsung corporations following a series of allegations raised by Samsung's former chief attorney. Many crisis communication researches recommend to do a strategic communicative response by assessing the crisis situation and selecting an image restoration strategy that best fits the crisis situation (Benoit, Czerwinski; Brinson \& Benoit, 1999; Coombs, 1998; Coombs \& Holladay, 2002; Coombs \& Schmidt, 2000). The crisis management team responding to the allegations of organizational wrongdoing by a whistleblower should consider the characteristics associated with the wrongdoing as well as the general perceptions of key stakeholders including shareholders, business partners, government officials, media, and opinion leaders in the society.

The characteristic of a crisis that is used by various publics to interpret the event is largely determined by the crisis responsibility, or how much the organization is to blame for the event (Coombs, 1998). The degree of crisis responsibility is generally influenced by severity and performance history. Severity is "the amount of damage generated by a crisis including financial, human, and environmental damage" and performance history refers to "the past actions or conduct of an organization including its crisis history and relationship history" (Cooms \& Holladay, 2002, p. 169). Public opinion attributes greater crisis responsibility to the organization when high severity and repeated negative performance history were perceived. Coombs \& Holiday (2002)'s research has also found that if the case belongs to the preventable crisis cluster (e.g., organizational misdeeds), it usually generates strong attribution of crisis responsibility.

Considering the severity (e.g., Samsung was alleged to create a slush fund of \$205 million via fraudulent accounting to routinely bribe government officials, prosecutors and the press) and performance history (e.g., In 1996 and 2003, Samsung executives were indicted with similar charges when they helped promote the illegal management transfer from father to son), Samsung could have lessened the damage by making immediate gestures of mortification and taking corrective actions at the outbreak of the allegations. It is also regretful that the whistle-blower came forward in October 2007 and Mr. Lee did not take responsibility until April 2008. There was an unnecessary delay in the admission that ended the crisis. Coombs says "the terms quick and quickly are synonymous with crisis response" (2007, p. 128). He also cautions the primary risk associated with speed is the potential for inaccuracies (Smith \& Hayne, 1997). In practical terms, a strategy to shorten the length of the crisis, thus preventing prolonged damage to Samsung's public image, was not employed. In terms of the command to 'get it all out, get it out quickly, and get it yourself', Samsung fell short on counts one and two. In addition, the acceptance of responsibility is not likely to be subject to errors of fact, but rather a question of judgment.

Against a crisis of high severity and repeated negative performance history, Coombs (Coombs, 2007, p. 143) also suggested the use of corrective action or diminishment strategies in his SCCT (Strategic Crisis Communication Theory). However, Samsung consistently denied the organizational wrongdoings and relied heavily on attacking the accuser until the special council unveiled a list of 1,300 slush fund accounts under the names of more than 1,000 former and current Samsung executives. Samsung's crisis management team might consider that Samsung's past and current reputations and contributions to the national economy transcend the recognized crisis responsibility. Samsung monitored public opinion and confidently employed the image restoration strategies of "transcendence."

In South Korea, Samsung is not just an individual company but a foundation of the national economy, which accounts for fifteen percent of GDP and twenty percent of exports. As the mission statement of Samsung put it, "economic contribution to the nation", Samsung also strongly identifies itself with the state of the national economy. Samsung's unequivocal significance to the national economy explains why virtually no South Korean maintains that Samsung should follow the way of Enron of US. Ironically, to the average South Korean, Samsung is a double-edged sword: pride and humiliation. Even though South Koreans have grown tired of the corrupt ways of their big businesses including Samsung, they are proud of Samsung's splendid achievements in the competitive global market. Even after the special council's investigation, a South Korean opinion poll showed that Samsung was chosen as a most favored company $(34.7 \%)$ by college students followed by LG (20.9\%) and Hyundai (18.2\%) (Lim, 2008). The positioning of Samsung in the South Korean national economy and the ambivalent feelings of stakeholders against Samsung explain why the choice of transcendence image restoration strategy might be the best one protecting Samsung's positive reputation. In spite of sporadic public outcry against disappointing outcomes from the special investigation, Samsung seemed to pass the crisis of whistle blowing without scathing much of its management structure and corporate image.

However, lessons of crisis management insist that choices and implementation of crisis response strategies should be a learning experience for the future crisis (Barton, 2001). An important condition for renovating an organizational culture is the need for corrective action and change following the crisis. If organizations do not illustrate to their stakeholders that they are committed to rebuilding and correcting the problem, similar types of crises could happen again. Most allegations against Samsung over time are basically grounded on the family-owned management structure and the Lee family's attempt to transfer its wealth to the next generation without taking the proper legal steps. Without touching fundamental problems, Samsung's promise to overhaul and change its management system and 
policies suggests the changes could be superficial, which may result in more allegations in the near future.

Image restoration is a process of winning the marketplace of ideas by interpreting what (how) has happened and who is at fault. Image restoration strategies of transcendence as well as denial and attacking the accuser do not carry meaningful and observable actions that essentially renew or correct the problems. Even though defensive rhetoric constitutes the core component of a crisis response process (1995), specific behavioral provisions of what will be corrected are fundamental to restore a ruined corporate image. As a number of scholars put it, the meaning of crisis connotes both disaster and opportunities. Crises can be used as a chance for image restoration, improvement and organization renewal when strategies work together under the auspice of strong leadership.

This study provides a unique application of Benoit's image restoration theory to the explanation of how a South Korean corporation responded to the whistle blowing attack by a disgruntled insider in a different cultural context. This study provides evidences that the selection of image restoration strategies (e.g., transcendence) counts on in-depth considerations of the unique characteristics of cultural context and audiences involved. To extend the validity and applicability of the Benoit's template to diverse situations, more research should be done to verify how moderating variables, such as culture, organizational structure, or audience characteristics, interact with image restoration variables.

\section{REFERENCES}

Barton, L. (2001). Crisis in Organizations II. Phoenix: Dave Shaut.

Benoit, W. L. (1995). Accounts, Excuses, and Apologies: A Theory of Image Restoration Strategies. Albany: State University of New York Press.

Benoit, W. L. (1997). Image repair discourse and crisis communication. Public Relations Review, 23(2), 177-186.

Benoit, W. L. (2006). Image repair in president Bush's April 2004 news conference. Public Relations Review, 32, 137-143.

Benoit, W. L. (Czerwinski) (1997). A critical analysis of USAir's image repair discourse. Business Communication Quarterly, 60(3), 38-57.

Benoit, W. L., \& Brinson, S. L. (1999). Queen Elizabeth's image repair discourse: Insensitive royal or compassionate queen? Public Relations Review, 25(2), 145-156.

Benoit, W. L., \& Czerwinski, A. (1997). A critical analysis of USAir's image repair discourse. Business Communication Quarterly, 60(3), 38-57.

Brinson, S. L., \& Benoit, W. L. (1999). The tarnished star: Restoring Texaco's damaged public image. Management Communication Quarterly, 12(4), 483-510.

Choe, S. (2007a, November 6). Corruption Scandal Spreads at Samsung. New York Times.

Choe, S. (2007b, December 4). Tired of Corruption but Afraid of the Crackdown. New York Times.
Coombs, W. T. (1998). An analytic framework for crisis situations: Better resposes from a better understanding of the situation. Journal of Public Relations Research, 10(3), 177-191.

Coombs, W. T. (2007). Ongoing Crisis Communication: Planning, Managing, and Responding (2nd ed.). California: Thousand Oaks: Sage Publications, Inc.

Coombs, W. T., \& Holladay, S. J. (2002). Helping crisis managers protect reputational assets: Initial tests of the situational crisis communication theory. Management Communication Quarterly, 16(2), 165-186.

Coombs, W. T., \& Schmidt, L. (2000). An empirical analysis of image restoration: Texaco's racism crisis. Journal of Public Relations Research, 12(2), 163-178.

Cooms, W. T., \& Holladay, S. J. (2002). Helping crisis managers protect reputational assets: Initial tests of the situational crisis communication theory. Management Communication Quarterly, 16(2), 165-186.

Elwood, W. N. (1995). Public Relations Inquiry as Rhetorical Criticism: Case Studies of Corporate Discourse and Social Influence. In W. N. Elwood (ed.), Public Relations in a Rhetorical Experience: The Integral Principle in Case Study Analysis. Westport: CT: Praeger.

Jin, D. (2007, November 13). Nominee for Highest Prosecution Post Bribed. Korea Herald.

Kim, S. (2007a, November 24). Lawmakers Pass Special Probe on Samsung Group. Korea Herald.

Kim, S. (2007b, November 23). Parties Agree to Pass Samsung Probe Bill. Korea Herald.

Kim, S. (2007c, November 26). Prosecutors Ban Samsung Officials from Leaving Nations. Korea Herald.

King, G. (2006). Image restoration: An examination of the response strategies used by Brown and Williamson after allegations of wrongdoings. Public Relations Review, 32, 131-136.

Lee, S. (2007, November 17). Business Opposes Samsung Probe. Korea Herald.

Lee, S., \& Jin, H. (2008, April 18). Samsung to Issue Reform Plan Next Week. Korea Herald.

Len-Rios, M., \& Benoit, W. L. (2004). Gary Condit's image repair strategies: determined denial and diffierentiation. Public Relations Review, 30, 95-106.

Lim, J. W. (2008, January 25th.). Samsung Most Preferred Even After Special Investigation. Yonhap News.

Near, J. P., \& Miceli, M. P. (1985). Organizational dissidence: The case of whistle-blowing. Journal of Business Ethics, 4, 1-16.

Seeger, M. W., \& Ulmer, R. R. (2002). A post-crisis discourse of renewal: The cases of Malden Mills and Cole Hardwoods. Journal of Applied Communication Research, 30, 126-142.

Smith, C. A. P., \& Hayne, S. C. (1997). Decision making under time pressure: An investigation of decision speed and decision quality of computer supported groups. Management Communication Quarterly, 11(1), 97-126.

Song, S. (2007a, November 14). Samsung Sues Lawyer over Bribery Allegations. Korea Herald.

Song, S. (2007b, November 6). Whistle-Blower Lashes Out at Samsung. Korea Herald.

Song, S. (2008a, April 5). Samsung Chairman Lee Questioned. Korea Herald.

Song, S. (2008b, April 18). Samsung Chairman, 9 Executives Indicted. Korea Herald.

Ulmer, R., Seeger, M., \& Sellnow, T. L. (2007). Post-crisis communication and renewal: Expanding the parameters of post-crisis discourse. Public Relations Review, 33, 130-134.

Zhang, J., \& Benoit, W. L. (2004). Message strategies of Saudi Arabia's image restoration campaign after 9/11. Public Relations Review, 30, 161-167.

Received: February 21, 2011

Revised: May 17, 2011

Accepted: May 20, 2011

(C) Jung et al:; Licensee Bentham Open.

This is an open access article licensed under the terms of the Creative Commons Attribution Non-Commercial License (http://creativecommons.org/licenses/by-nc/3.0/) which permits unrestricted, non-commercial use, distribution and reproduction in any medium, provided the work is properly cited. 